\title{
Foraging behaviour of the crab Cancer pagurus feeding on the gastropods Nucella lapillus and Littorina littorea: comparisons with optimal foraging theory
}

\author{
P. Lawton* \& R. N. Hughes \\ School of Animal Biology, University College of North Wales, Bangor, Gwynedd LL57 2UW, United Kingdom
}

\begin{abstract}
Juvenile Cancer pagurus used the left and right chelae with equal facility to immediately crush small Nucella lapillus and Littorina littorea, and to gradually chip away the shells of larger snails. Due to slippage of the chela over the apical whorls, attacks directed towards the shell aperture of larger prey were more successful than those applied to the spire. Attack success rate decreased from unity at the critical size for crushing to zero at the critical size for apertural breakage, falling more rapidly for $N$. lapillus than for $L$. littorea. Handling times rose rapidly for $N$. lapillus as prey exceeded critical size for crushing and consequently the maximum yield per unit handling time coincided with this critical size. Maximum yield for $L$. littorea was within the range of sizes that were opened by apertural breakage. Profitability curves derived from single regressions of yield and of handling time on prey size failed to predict profitability accurately. Satisfactory curves were obtained by combining separate handling time functions for prey below and above the critical size for immediate crushing. When offered a range of prey sizes, C. pagurus attacked all size classes, but incorporated smaller prey into the diet first as they succumbed more frequently to attack. The greater susceptibility of L. littorea was reflected in differential predation on this species when offered together with $N$. lapillus. Contrary to optimal foraging expectations of short persistence times when prey are of variable and relatively unpredictable profitability, C. pagurus persisted for up to several hours with large prey. Thus prey-size selectivity appeared to have a passive mechanical, rather than an active behavioural basis.
\end{abstract}

\section{INTRODUCTION}

Considerable attention has been directed in recent years to the analysis of predator behaviour from the perspective of optimal foraging theory (reviewed by Pyke et al. 1977, Hughes 1980, Pyke 1984). Studies on the size selection of molluscs by crabs (Decapoda: Brachyura) have contributed both to theoretical development and empirical testing of predictions based on optimal foraging premises (Elner \& Hughes 1978, Hughes 1979, Hughes \& Elner 1979, Hughes \& Seed 1981, Blundon \& Kennedy 1982, Jubb et al. 1983 , Arnold 1984). The majority of such studies pertain to crabs from a single family (Decapoda: Portunidae) and,

\footnotetext{
- Present address: Marine Sciences Research Center, State University of New York at Stony Brook, Long Island, New York 11794-5000, USA
}

more significantly, to 1 species within that family, Carcinus maenas. The aim of the present study is to test the generality of optimal foraging rules proposed for portunid crabs by using Cancer pagurus (Decapoda: Cancridae), a brachyuran crab with different morphological, physiological and behavioural attributes (Wamer \& Jones 1976, Vermeij 1977, Lawton \& Elner 1985). Laboratory experiments involving Cancer pagurus feeding on 2 gastropod species are here described which characterize: (1) attack methods used during predation attempts and proportional attack success in terms of crab size and sex, chelal morphology, gastropod size and shell morphology; (2) the form of handling time and profitability relations taking such factors into account; (3) the extent to which prey-size selectivity of Cancer pagurus on gastropods reflects passive mechanical or active behavioural mechanisms of choice (sensu Hughes 1980). 
In North Wales, the direct-developing gastropod Nucella lapillus is often sympatric with Littorina littorea, a species having a pelagic larval stage. Hughes $\&$ Elner (1979) found that local populations of $N$. lapillus, coexisting with large populations of the portunid crab, Carcinus maenas, were more robust, with narrower apertures than those from sites where these crabs were absent. These features increased gastropod resistance to crab-attack, and were even more pronounced in a sublittoral fringe population of $N$. lapillus coexisting with Cancer pagurus. Such inter-population variation in shell morphology is much reduced or absent in L. littorea. Gene flow between populations during the pelagic larval stage of this species may preclude morphological adaptation to local selection factors (Currey \& Hughes 1982). Collection sites for these species, around the Isle of Anglesey, North Wales, were selected so that 2 additional questions could be addressed in the study: (1) Is $C$. pagurus predation potentially responsible for the pronounced morphological attributes of sublittoral fringe $N$. lapillus? (2) What are the consequences, for susceptibility to predation, of reduced levels of morphological adaptation in L. littorea?

\section{MATERIAL AND METHODS}

General procedures. Juvenile Cancer pagurus and the gastropods Nucella lapillus and Littorina littorea were collected on ELWS tides from local shores (Table 1). Due to the low availability of small-to medium-sized L. littorea at the Penmon site, feeding trials with this species used snails of these sizes from Llanddwyn Island (Table 1) to supplement material from Penmon. L. littorea from the 2 localities have similar morphological characteristics, with the exception that some individuals from Llanddwyn Island show marked apical shell erosion (Lawton 1983).

Crabs were each placed in separate $40 \times 20 \times 25$ $\mathrm{cm}$ (height) clear plastic aquaria filled to $20 \mathrm{~cm}$ with recirculating filtered seawater. Salinity was maintained at 33.5 to $37.0 \%$ and water temperatures fol- lowed ambient air temperatures of 12.8 to $19.0^{\circ} \mathrm{C}$. Artificial lights were regulated to seasonal photoperiod. Prior to a feeding trial crabs were satiated with flesh of the prey species to be tested, then starved for $2 \mathrm{~d}$ to standardize hunger level (Jubb et al. 1983). Cancer pagurus of a wide size range (carapace width, $\mathrm{cm}$ ) were used in preliminary trials; however, in subsequent experiments crabs from only 3 size classes were used: small $(5.5$ to $6.5 \mathrm{~cm})$, medium $(7.5$ to $8.5 \mathrm{~cm})$, and large $(9.5$ to $10.5 \mathrm{~cm})$. Gastropod prey were similarly categorized into particular size classes (shell height, $\mathrm{cm})$.

Enumeration data were analysed by the Log-likelihood ratio, $G$, using observed frequencies, and applying Yates' correction for continuity to derive an adjusted $\mathrm{G}$ in goodness-of-fit tests with only 2 classifications (Zar 1974). Other parametric statistical procedures were obtained from Zar (1974); non-parametric statistics were computed according to Siegel (1956).

Attack methods. Church Island Nucella lapillus of 0.5 to $2.1 \mathrm{~cm}$ shell height and Littorina littorea of 0.5 to $3.1 \mathrm{~cm}$ shell height were presented, individually, to male and female crabs of 5.5 to $12.5 \mathrm{~cm}$ carapace width. Behavioural responses to the prey and details of each attack sequence made by each crab were recorded, together with the success or failure of the attack.

Attack success rate. Male and female crabs from each of the 3 size classes ( $n=6$ to 7 per size class) were presented with Church Island Nucella lapillus of 0.8 to $2.5 \mathrm{~cm}$ shell height, subdivided into 4 size classes. The proportion of successful attacks was calculated from 10 attacks for each combination of predator-prey size class.

A less detailed examination of attack success rate was undertaken for Littorina littorea by determining the critical shell height (sensu Vermeij 1976) for complete crushing of smaller prey, corresponding to the maximum size for an attack success rate of unity, and the critical shell height for apertural breakage, corresponding to the maximum size for an attack success rate greater than zero. Twelve male crabs $(5.5$ to $10.7 \mathrm{~cm}$ carapace width) were each initially presented with

Table 1. Isle of Anglesey, North Wales. Location (Ordnance Survey map reference) and exposure grade (Lewis 1964) of each collection site together with the maximum size recorded for Cancer paguns (carapace width, cm), Nucella lapillus and Littorina littorea (shell height, $\mathrm{cm}$ ) during intertidal searches. Consult Lawton (1983) for a more detailed description of the sites

\begin{tabular}{|lcccccc}
\hline Site & Location & Exposure grade & \multicolumn{2}{c}{ Maximum size recorded } \\
& & & Cancer pagurus & Nucella lapillus & Littorina littorea \\
\hline Llanddwyn Island & SH386628 & 1 & Not found intertidally & 3.3 & 2.6 \\
Penmon & SH638816 & $3-4$ & 8.8 & 3.9 & 3.4 \\
Church Island & SH552716 & $4-5$ & 13.2 & 4.2 & 3.2 \\
\hline
\end{tabular}


5 small L. littorea. Eaten prey were replaced daily with progressively larger individuals until 5 d elapsed without further predation.

Handling time. Male and female crabs from the 3 size classes ( $n=6$ to 7 per size class) were presented individually with Church Island Nucella lapillus of 0.5 to $2.0 \mathrm{~cm}$ shell height. Crabs were starved for $24 \mathrm{~h}$ between consecutive presentations to standardize hunger level. Methods of attack were noted and the following behavioural sequences timed: (1) if a prey was rejected, 'persistence time' was measured as the time from the moment the crab grasped the prey until rejection; (2) if a prey was not rejected, 'breaking time' was measured as the time from the moment the crab grasped the prey to the first bite of flesh exposed by breaking the shell; (3) 'eating time' was measured as the time from the first bite of flesh to abondonment of the prey, including intermittent periods of shell breakage and inspection of shell debris towards the end of the meal. 'Handling time' was calculated as the sum of breaking time and eating time.

Four medium-sized male crabs were then divided into 2 pairs. One pair of crabs was presented with a range of sizes of Penmon Nucella lapillus and the handling episodes timed. Handling times were recorded for the other pair as they preyed upon Littorina littorea.

Profitability. The yield of flesh from Church Island Nucella lapillus was estimated from a regression of $\log _{e}$ (dry flesh weight) on $\log _{e}$ (shell height). Data were obtained by removing the flesh from $N$. lapillus of 0.5 to $2.5 \mathrm{~cm}$ shell height, drying the flesh for $48 \mathrm{~h}$ at $60^{\circ} \mathrm{C}$, weighing the dried flesh and applying an energy conversion factor of $21.97 \mathrm{~kJ} \mathrm{~g}^{-1}$ (Hughes 1972). Similar data were obtained for Penmon $N$. lapillus and Littorina littorea. 'Profitability', the yield of flesh per unit handling time (Hughes 1980), was estimated by dividing the yield of flesh predicted by regression by each measurement of handling time. Curves relating profitability to prey size were derived by dividing the regression equation for yield of flesh by the appropriate equation for handling time, both with and without adjustment for size-specific attack success rates.

Prey-size selection. Prey-size selection was observed when crabs were presented with Church Island Nucella lapillus, Penmon N. lapillus and Littorina littorea, all maintained in equal numbers by replacing injured as well as eaten prey (unlimited availability), and with Church Island $N$. lapillus that were not replaced as injured or eaten (limited availability).

Unlimited Nucella lapillus: 4 medium-sized male crabs were presented with 5 Church Island $N$ lapillus from each of 4 size classes (indicated in Table 2), placed haphazardly over the aquarium bottom for each crab. All $N$. lapillus were inspected and debris removed daily for $10 \mathrm{~d}$, replacing injured or eaten prey with fresh ones of a similar size. The procedure was repeated for 4 medium-sized male crabs presented with Penmon N. lapillus.

Unlimited Littorina littorea: 2 male crabs from each of the 3 predator size classes were presented for $10 \mathrm{~d}$ with $5 \mathrm{~L}$. littorea from each of 3 or 4 size classes (indicated in Table 2), dependent on crab size. Because L. littorea, unlike Nucella lapillus, tended to crawl up the aquarium walls and remain out of reach of the crabs, they were immobilized before experimentation by immersion in fresh water at $40^{\circ} \mathrm{C}$ for $15 \mathrm{~min}$, followed by immersion in sea water at ambient air temperature for $10 \mathrm{~min}$. This treatment stimulated the animals to retract into the shell. Other experimental details were as described above for $N$. lapillus.

Unlimited mixture of Nucella lapillus and Littorina littorea: 4 medium-sized male crabs were each presented for $7 \mathrm{~d}$ with 5 Penmon $N$. lapillus and $5 \mathrm{~L}$. littorea from each of 3 size classes (indicated in Table 3). The N. lapillus were heat-treated similarly to the L. littorea. A pair of crabs fed treated and untreated $N$ lapillus did not respond differentially to either prey (adjusted $\mathrm{G}=2.1$, d.f. $=1, \mathrm{P}>0.05$ ).

Limited Church Island Nucella lapillus: 2 male crabs from each of the 3 predator size classes were each presented initially with $10 \mathrm{~N}$. lapillus from 3 or 4 size classes (indicated in Fig. 6), the range in prey size being dependent on crab size. Prey were not replaced as eaten, so that exploited size classes became depleted over the $10 \mathrm{~d}$ experiment. Debris was removed daily but injured prey were left in the aquaria.

\section{RESULTS}

\section{Attack methods}

An olfactory response to prey was recognizable by the synchronous orientation of the antennules towards the prey together with an increase in antennular flicking rate. Following contact, prey were either swept under the abdomen and forward towards the chelipeds using the pereiopods, or swept inward by lateral extension and flexion of a cheliped. The prey was grasped most frequently with the right cheliped (adjusted $\mathrm{G}=4.0$, d.f. $=1, \mathrm{P}<0.05$ ), then both chelipeds were drawn together in front of the mouth. Relatively small prey that were dropped during these actions were seldom recovered. Prey were manipulated by the 3rd maxillipeds and chelae, the 1 st and 2 nd pereiopods providing additional support for large prey. Such manipulations were frequent before crabs attempted to break the shell and occurred intermittently during breakage. 
Nucella lapillus

Three methods of attack were recognizable:

(1) Crushing. Small Nucella lapillus were completely crushed with equal probability by either chela (adjusted $\mathrm{G}=2.5$, d. f. $=1, \mathrm{P}>0.05$ ). The chela used to crush the prey was usually the one that initially had picked it up $(G=15.6$, d. f. $=3, P<0.005)$, the other chela being used to support the prey during breakage. Crushing involved repeated applications of force accompanied by slight reorientations of the prey within the chelal gape. Of 32 small $N$. lapillus crushed in this manner, 26 were broken by a single crushing sequence, 4 by 2 crushing sequences separated by oral manipulation, and 2 by 3 crushing sequences.

(2) Apertural breakage. The propodus or dactylus of 1 chela was inserted into the shell aperture and the columella grasped. The other chela then broke away the shell lip opposite the columella. Either chela was used with equal facility to hold or break the shell in such attacks. Applications of force were interspersed with periods of reorientation that became more frequent with larger prey. The technique was successful in 98 cases out of 164 observed attacks on large Nucella lapillus. Shell lip material was readily removed up to the point of maximum retraction of the snail. The operculum then obstructed further insertion of the dactyli and 64 attacks were observed to fail at this stage.

(3) Apex removal. Crabs frequently grasped the columella with 1 chela while attempting to crush the apex of the shell with the other. This technique was only rarely successful (in 2 cases), the process being hindered by slippage of the chela over the apical shell whorls.

\section{Littorina littorea}

Prey opening techniques were comparable to those used on Nucella lapillus with some qualifications due to the larger shell aperture and thinner shell of Littorina littorea. At prey sizes just above the maximum crushed outright, the shell was completely broken by indiscriminate attacks to the apertural margin. At larger sizes attacks were directed to the centre of the shell lip, leaving a spiral gash along the whorls and the columella intact. Towards the critical prey size, the apices of some shells could not be opened completely, resulting in only partial prey consumption. At these large prey sizes the operculum of L. littorea was effective in protecting against crab attack. Crabs were frequently observed attempting to remove the apices of $L$. littorea, but this technique was never successful, even with Llanddwyn Island snails showing marked apical shell erosion.

\section{Attack success rate}

\section{Nucella lapillus}

The proportion of successful attacks, based on data for all methods of attack, was not significantly different between male and female crabs within any predatorprey size class (Log-likelihood ratio, all $\mathrm{P}>0.05$ ) Attack success rates declined steeply from unity at the critical size for crushing to zero at the critical size for apertural breakage (Fig. 1A). These critical sizes increased with increasing crab size but for crabs of a given size they spanned no more than a $0.8 \mathrm{~cm}$ increment in shell height of the prey (Fig. 1A).

\section{Littorina littorea}

Critical size for crushing and apertural breakage were separated by an increment in shell height of about 1.0 to $1.5 \mathrm{~cm}$ (Fig. 1B). These critical sizes increased almost in parallel as crab size increased, the
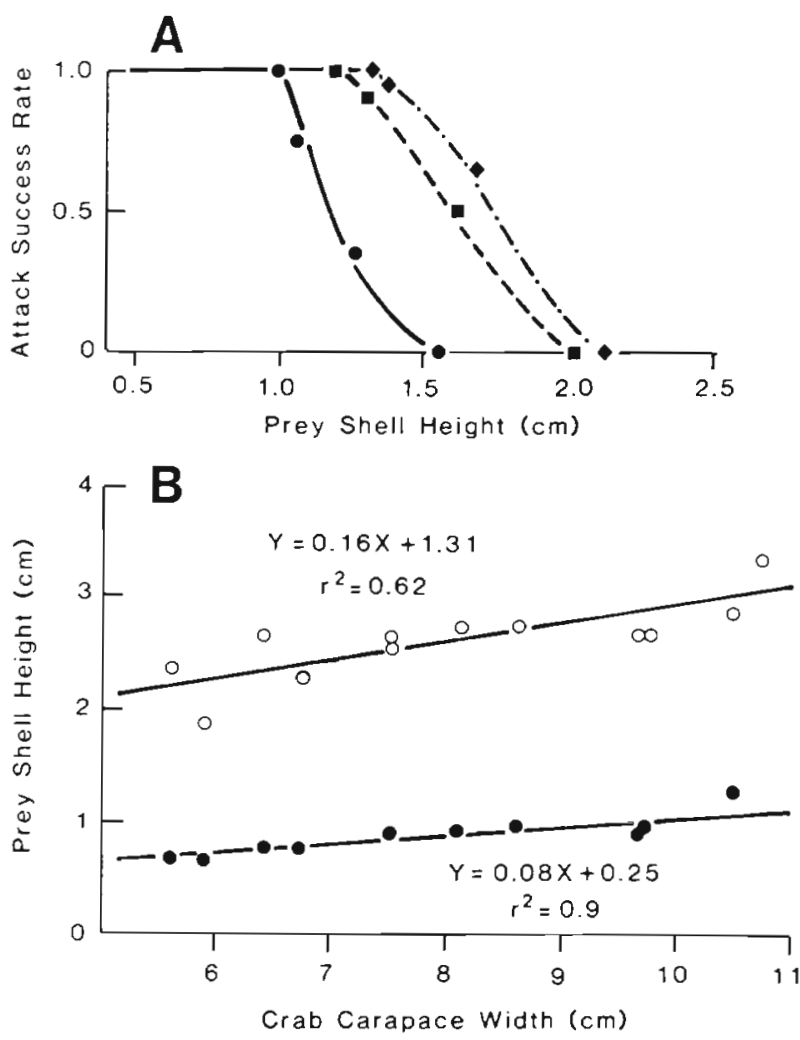

Fig. 1 Cancer pagurus. (A) Attack success rate on Church Island Nucella lapillus. Curves fitted by eye. Crab size classes: small $(\bullet$; medium (ロ); large $(\bullet)$. (B) Critical sizes of Littorina littorea susceptible to crushing $(\bullet)$ and apertural breakage (O). Critical sizes defined as mean size of largest shell broken by an attack method, and smallest size resistant to breakage by that method 
critical size for crushing being less variable than that for apertural breakage (Fig. 1B).

\section{Handling time}

Persistence time, in unsuccessful attacks on Church Island Nucella lapillus, increased with increasing prey size, but there was much variation about the trend (Fig. 2).

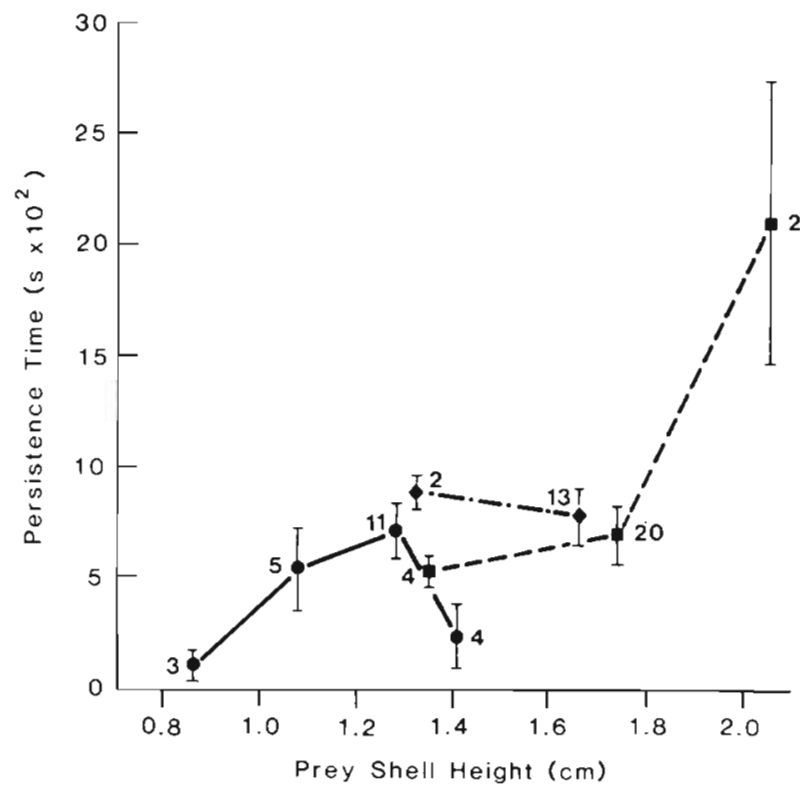

Fig. 2. Cancer pagurus. Mean persistence time (with SE and number of observations) in unsuccessful attacks on Church Island Nucella lapillus. Symbols for crab size class as in Fig. $1 \mathrm{~A}$

Handling time components of successful attacks (breaking time, handling time) appeared to be accelerating functions of prey size, and for a given sized prey were longer for smaller crabs, although there was considerable variation at large prey sizes (Fig. 3 \& 4). Initial regression analysis involved determining the fit of linear, exponential and power functions to data from each size class (irrespective of attack method). Whereas exponential and power functions gave significant improvements in fit to breaking time data over linear functions, differences between the correlation coefficients of these functions were not significant (Fisher's transformation, all $\mathrm{P}>0.05$ ) in any size class (Fig. 3). A similar result was obtained for handling time data, and only parameters for exponential functions are displayed (Fig. 4).

Using data from all 3 size classes, multiple linear regression, with a dependent variable of $\log _{\mathrm{e}}$ (breaking time) on prey shell height with dummy independent variables of crab size, sex and attack method,
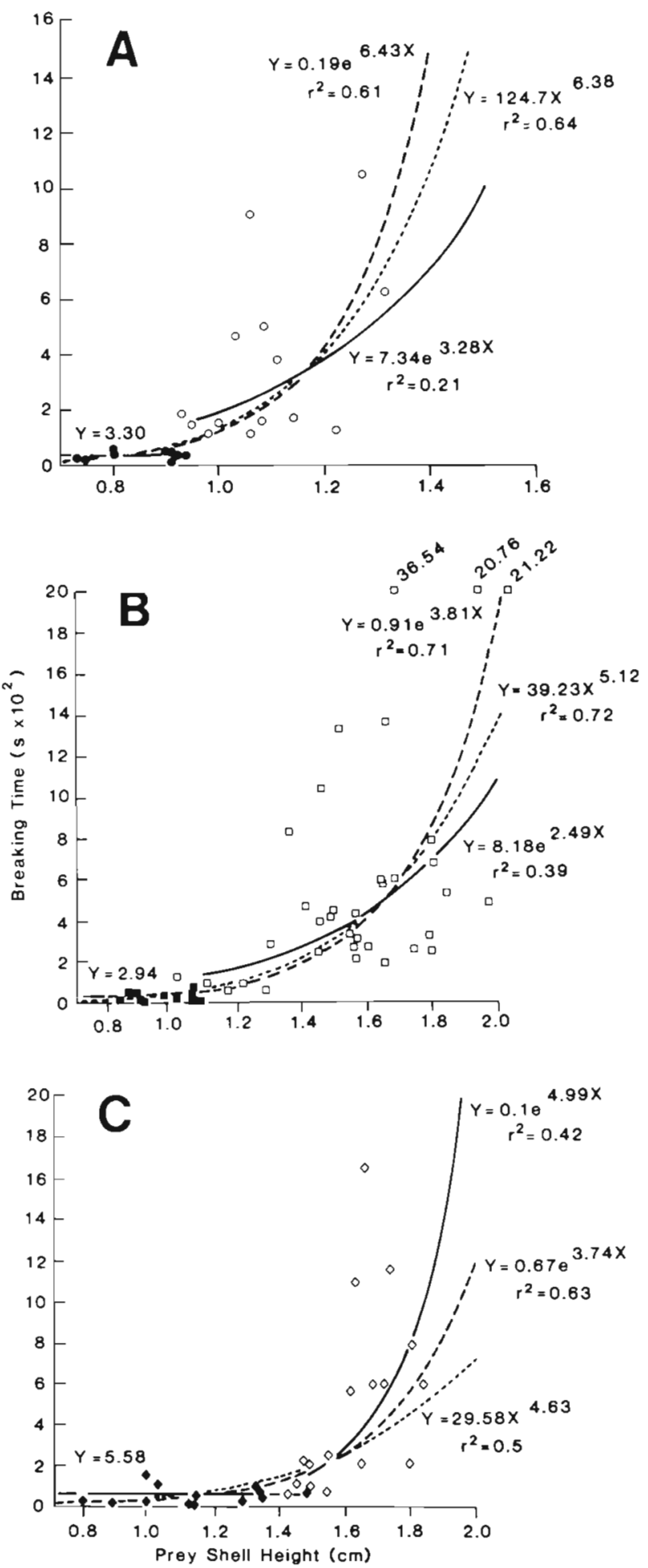

Fig. 3. Cancer pagurus. Breaking time in successful attacks on Church Island Nucella lapillus. Crab size classes: (A) small; (B) medium; (C) large. Solid symbols indicate that crushing was used, open symbols that apertural breakage was used as the attack method. Values for exceptionally long breaking times offset diagonally above data points. Regression functions: dual function ( -$)_{\text {i }}$ exponential $(---)_{\text {i }}$ power $(--)$. Vertical and horizontal scales in $\mathrm{A}$ differ from those in $\mathrm{B}$ and $\mathrm{C}$ 

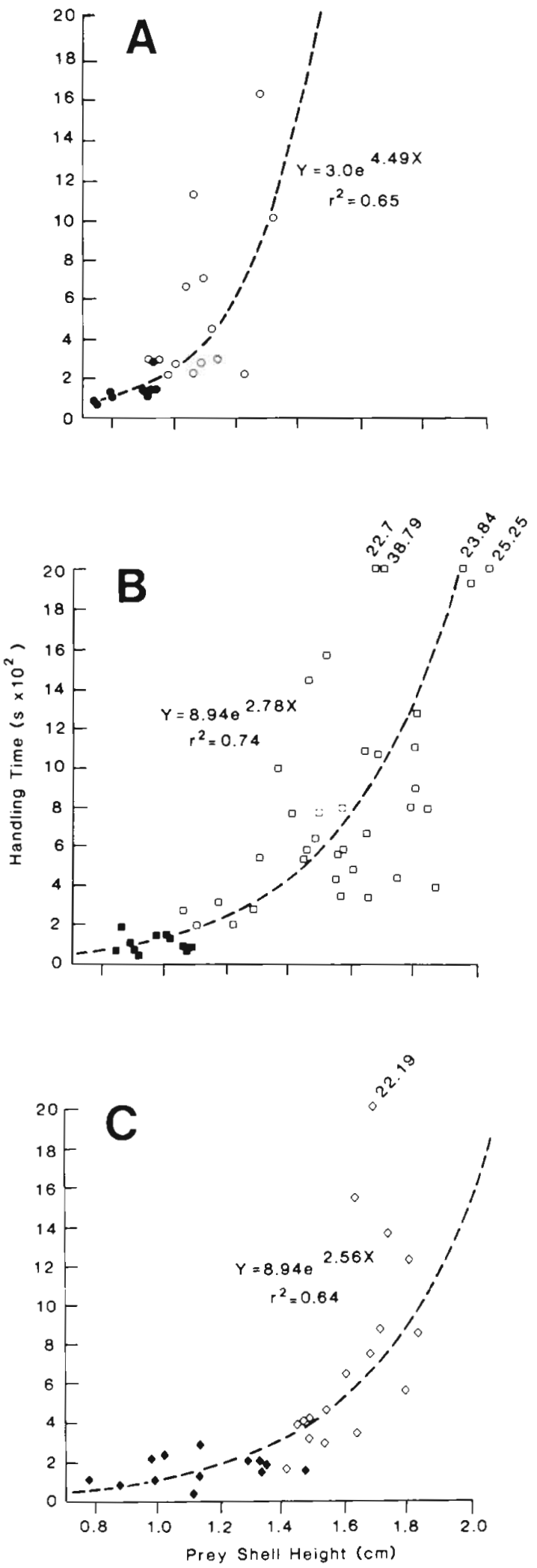

Fig. 4. Cancer pagurus. Handling time in successful attacks on Church Island Nucella lapillus. Plotting details as in Fig. 3. except that scales in A are consistent with those in B and $C$ showed sex not to be a significant determinant of breaking time $(P>0.10)$, whereas crab size, prey size and attack method were all significant (all $\mathrm{P}<0.001$ ). Interactions between the independent variables were not significant (all $P>0.05$ ). In view of this result, a dual function analysis of the breaking time relation was performed. Breaking time for prey that were crushed was not significantly dependent on prey size $(\mathrm{P}>0.05)$ or on crab size $(\mathrm{P}>0.25)$, the mean value for the pooled data being $42.5 \pm 29.3 \mathrm{~s}$ (SE). For prey opened by the apertural breakage method both prey size $(P<0.0001)$ and crab size $(P<0.001)$ were significant determinants of breaking time. Exponential and power functions gave equally good fits to the apertural breakage data for crabs in each size class (difference between correlation coefficients, Fisher's transformation, all $\mathrm{P}>0.05$ ) and only parameters of the exponential functions are given (Fig. 3).

\section{Profitability}

Yield of flesh was related to the size of Church Island Nucella lapillus by the regression equation: $\mathrm{y}=3.30 \mathrm{x}-2.29, \mathrm{n}=70, \quad \mathrm{I}^{2}=0.96$, where $\mathrm{y}=\log _{e}$ (flesh content, $\mathrm{kJ}$ ) and $\mathrm{x}=\log _{\mathrm{e}}$ (shell height, $\mathrm{cm}$ ).

When calculated with breaking time, the observed profitability of Church Island Nucella lapillus peaked at the critical size for crushing (Fig. 5). Profitability curves derived from exponential and power functions fitted to breaking time data (irrespective of attack method) failed to predict these high profitabilities. Closer correspondence to observed profitability was obtained when the constancy of breaking time for small prey was taken into account, as in the dual function analysis (Fig. 5). Inclusion of eating time tended to smooth the transition between the 2 breaking methods (compare Fig. 3 with Fig. 4), yielding profitability relations with less marked optima.

Using the limited data on handling time of Penmon Nucella Japillus and of Littorina littorea, together with regressions of predicted yield for these morphs (Lawton 1983), comparisons were made of the profitabilities of the 3 prey types to medium-sized Cancer pagurus (Fig. 6). Profitability curves for Penmon $N$. lapillus were comparable with those for Church Island N. Iapillus indicating an optimal size close to the critical size for crushing. L, littorea were considerably more profitable than both $N$. lapillus morphs, reaching an optimum within the range of sizes opened by apertural breakage. Adjustments for declining attack success rates at larger prey sizes steepened the descent, past the optima, but did not improve the fit to the data (Fig. 6). 

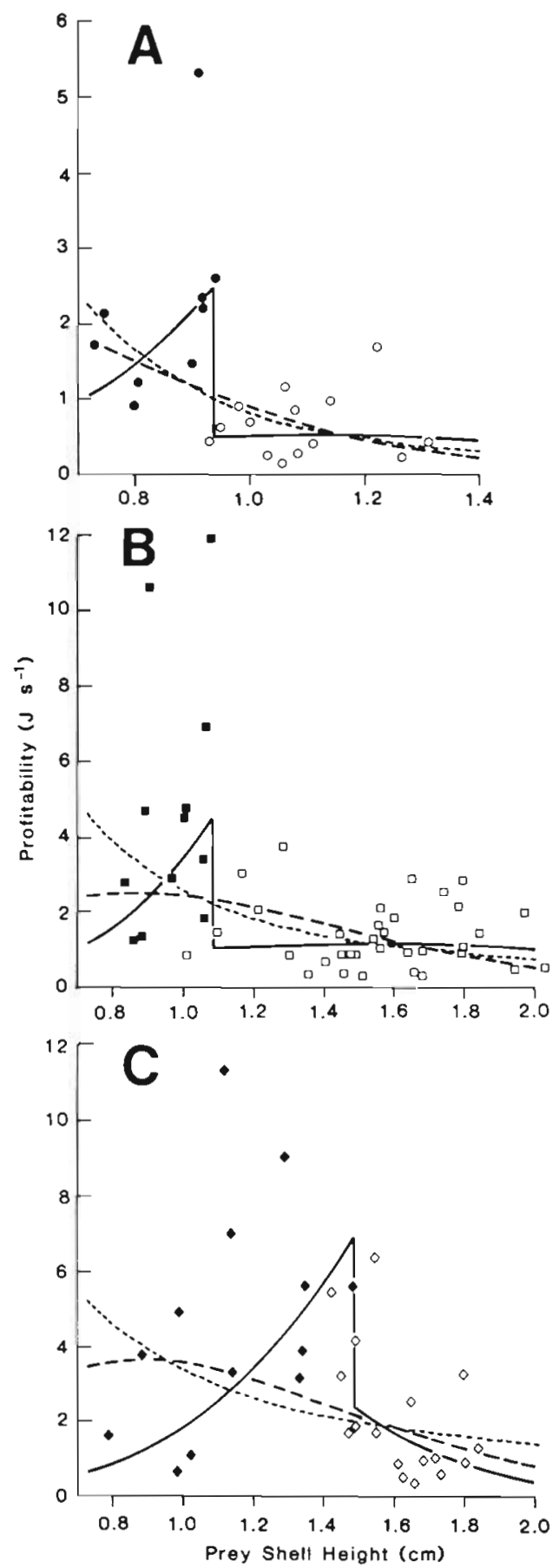

Fig. 5. Cancer pagurus. Profitability of Church Island Nucella lapillus expressed as the ratio of predicted yield to observed breaking time with profitability curves derived from single regression of yield on prey size (see text) and regression functions for breaking time (Fig. 3). Other plotting details as in Fig. 3

\section{Prey-size selection}

\section{Unlimited Nucella lapillus}

Attack frequencies and ingestion frequencies on Church Island Nucella lapillus over different prey

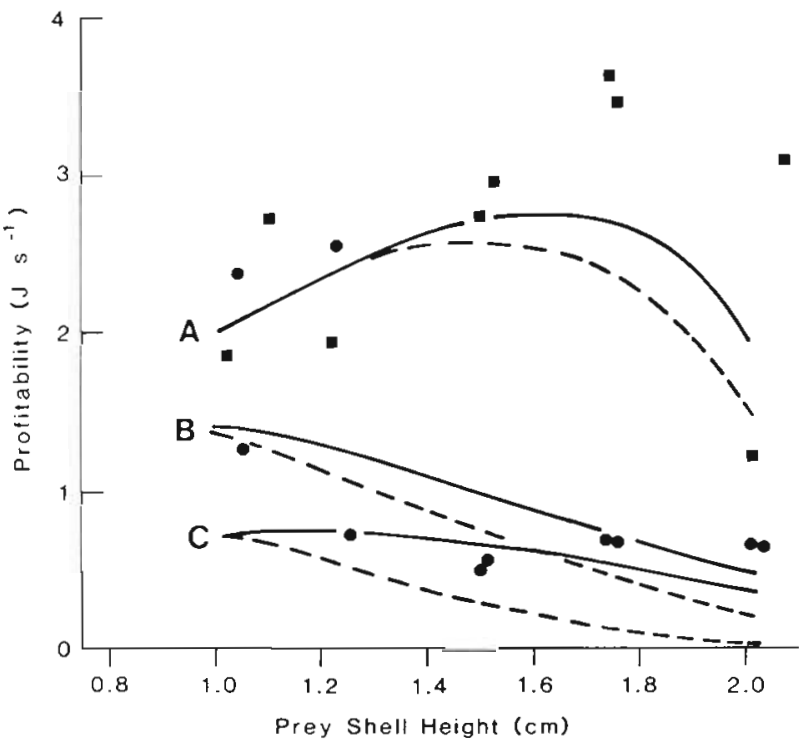

Fig. 6. Cancer pagurus. Profitability of 3 gastropod morphs to medium-sized crabs. Ratios of predicted yield to observed handling time are given for Littorina littorea ( $\square$ ) and Penmon Nucella lapillus $(\bullet)$. Profitability curves, derived from regressions of yield on prey size for each morph and exponential regressions fitted to observed handling times, are shown with $(-)$ and without (-) adjustment for size-specific attack success rates for (A) L. littorea; (B) Penmon N. lapillus; (C) Church Island $N$. lapillus

sizes were not significantly different among crabs (Table 2 , both $G<1.8, \mathrm{~d} . \mathrm{f} .=3, \mathrm{P}>0.5$ ). The number of prey attacked decreased from the smallest to the largest size class (Table 2, Friedman 2-way ANOVA by ranks, $\chi_{\mathrm{r}}^{2}=6.5$, d. f. $\left.=2, \mathrm{P}<0.05\right)$. Larger prey yielded less frequently to attack, the survivors sustaining injuries ranging from chipping of the apertural margin to opening of the whorl up to the point of maximum opercular retraction. Unsuccessful attacks continued unabated throughout the trials. The number of prey successfully opened and eaten decreased from the smallest to the largest prey (Table 2, Friedman test, $\chi_{\mathrm{r}}^{2}$ $=8.0$, d. f. $=2, \mathrm{P}<0.005$ ) .

Crabs differed significantly in their attack and ingestion frequencies on Penmon Nucella lapillus over different sized prey (Table 2 , both $G>16.5$, d. f. $=3$, $P<0.001)$. The number of prey attacked did not decrease significantly from the smallest to the largest size classes (Table 2, Friedman test, $\chi_{\mathrm{r}}^{2}=3.5$, d. f. $=2$, $P>0.25)$, but the numbers successfully opened and eaten did (Table 2, Friedman test, $\chi_{\mathrm{I}}^{2}=6.5$, d. f. $=2$, $\mathrm{P}<0.05$ ). There was a significant interaction between crab identity and prey size in the number of prey attacked $(G=15.9$, d. f. $=6, P<0.025)$.

\section{Unlimited Littorina littorea}

Crabs differed significantly in their attack and ingestion frequencies over different sized prey (Table 
Table 2. Cancer pagurus. Prey-size selection on 3 gastropod shell morphs presented with replacement. Values of mean daily attack frequency ( $\pm \mathrm{SE}, \mathrm{n}=10$ ) over $10 \mathrm{~d}$ for individual crabs. Proportional success (based on tota) attack frequency) on each prey size class is given in parentheses

\begin{tabular}{|c|c|c|c|c|c|}
\hline $\begin{array}{l}\text { Gastropod } \\
\text { shell morph }\end{array}$ & $\begin{array}{l}\text { Crab carapace width } \\
\text { (cm) }\end{array}$ & $1.0-1.5$ & $\begin{array}{l}\text { Prey size clas } \\
1.5-2.0\end{array}$ & $\begin{array}{l}\text { (1 height, cm) } \\
2.0-2.5\end{array}$ & $2.5-3.0^{a}$ \\
\hline $\begin{array}{l}\text { Church Island } \\
\text { Nucella lapillus }\end{array}$ & $\begin{array}{l}8.2 \\
8.3 \\
8.5 \\
8.6\end{array}$ & $\begin{array}{c}2.1 \pm 0.38 \\
(0.95) \\
2.1 \pm 0.38 \\
(0.95) \\
2.6 \pm 0.40 \\
(0.84) \\
1.7 \pm 0.42 \\
(0.94)\end{array}$ & $\begin{array}{c}0.7 \pm 0.33 \\
(0.43) \\
0.4 \pm 0.16 \\
(0.50) \\
0.5 \pm 0.22 \\
(0.20) \\
0.5 \pm 0.17 \\
(0.20)\end{array}$ & $\begin{array}{c}0.6 \pm 0.31 \\
(0.33) \\
0.6 \pm 0.22 \\
(0.16) \\
0.1 \pm 0.10 \\
(0) \\
0.3 \pm 0.21 \\
(0)\end{array}$ & \\
\hline $\begin{array}{l}\text { Penmon } \\
\text { Nucella lapillus }\end{array}$ & $\begin{array}{l}7.6 \\
7.7 \\
7.8 \\
8.6\end{array}$ & $\begin{array}{c}1.8 \pm 0.53 \\
(0.89) \\
1.6 \pm 0.34 \\
(0.81) \\
2.6 \pm 0.31 \\
(0.92) \\
2.0 \pm 0.36 \\
(0.95)\end{array}$ & $\begin{array}{c}1.1 \pm 0.31 \\
(0.27) \\
0.5 \pm 0.22 \\
(0.8) \\
1.8 \pm 0.47 \\
(0.67) \\
2.5 \pm 0.48 \\
(0.68)\end{array}$ & $\begin{array}{c}2.0 \pm 0.47 \\
(0.20) \\
0.5 \pm 0.22 \\
(0.20) \\
0.8 \pm 0.39 \\
(0.50) \\
1.8 \pm 0.33 \\
(0.56)\end{array}$ & \\
\hline Littorina littorea & $\begin{array}{l}6.4 \\
6.7 \\
7.5 \\
7.9 \\
9.7 \\
9.8^{b}\end{array}$ & $\begin{array}{c}1.8 \pm 0.36 \\
(0.89) \\
1.4 \pm 0.34 \\
(1.00) \\
4.6 \pm 0.22 \\
(0.98) \\
2.3 \pm 0.42 \\
(0.91) \\
4.1 \pm 0.41 \\
(0.98) \\
2.6 \pm 0.68 \\
(1.00)\end{array}$ & $\begin{array}{c}2.0 \pm 0.37 \\
(0.60) \\
0.8 \pm 0.36 \\
(0.75) \\
4.1 \pm 0.31 \\
(0.93) \\
2.5 \pm 0.48 \\
(0.88) \\
3.9 \pm 0.38 \\
(0.90) \\
3.6 \pm 0.57 \\
(1.00)\end{array}$ & $\begin{array}{c}0.8 \pm 0.36 \\
(0.50) \\
0.3 \pm 0.30 \\
(0) \\
2.2 \pm 0.42 \\
(0.50) \\
2.1 \pm 0.35 \\
(0.81) \\
2.6 \pm 0.43 \\
(0.70) \\
2.4 \pm 0.80 \\
(0.84)\end{array}$ & $\begin{array}{c}0.4 \pm 0.22 \\
(0.25) \\
1.4 \pm 0.57 \\
(0.27)\end{array}$ \\
\hline
\end{tabular}

2, both $\mathrm{G}>82.4$, d. f. $=5, \mathrm{P}<0.001)$. Neither the number of prey attacked nor the number eaten differed significantly among prey size classes (Table 2, Friedman test, all $\mathrm{P}>0.167$ ). There was a significant interaction between crab identity and prey size in the number of prey eaten $(\mathrm{G}=22.4$, d. f. $=10 \mathrm{P}<0.025)$.

\section{Unlimited mixture of Nucella lapillus and Littorina littorea}

Crabs differed significantly in their attack and ingestion frequencies among prey categories (species, size, Table 3, both $\mathrm{G}>14.4$, d.f. $=3$, $\mathrm{P}<0.005$ ). Interactions between crab identity and prey category were significant (attacks, $G=30.3$, d. f. $=15$, $\mathrm{P}<0.025$; ingestions, $\mathrm{G}=34.9, \mathrm{~d} . \mathrm{f} .=15, \mathrm{P}<0.01)$. The frequency of attack was significantly different among prey categories (Table 3 , Friedman test, $\chi_{\mathrm{I}}^{2}=$ 21.6, d. f. $=5, \mathrm{P}<0.001$ ) as was the frequency of those eaten (Friedman test, $\chi_{r}^{2}=18.7$, d. $f .=5, \mathrm{P}<0.01$ ).
Littorina littorea were more heavily preyed upon than Nucella lapillus, the largest $L$. littorea being eaten more frequently than the smallest $N$. lapillus (Table 3 ).

\section{Limited Church Island Nucella lapillus}

Crabs consistently opened and ate the smallest snails first, taking larger ones as the smaliest snails became depleted (Fig. 7). All sizes of snail, however, were attacked throughout the trials and shells of larger surviving prey were frequently damaged.

\section{DISCUSSION}

\section{Attack methods}

Crushing of smaller gastropods, changing to apertural breakage of larger ones, described herein for Cancer pagurus, are attack methods also used by 
Table 3. Cancer pagurus. Prey-size selection on 2 gastropod shell morphs presented at equal density and with replacement. Values of mean daily attack frequency $( \pm \mathrm{SE}, \mathrm{n}=7$ ) for individual crabs. Proportional success (based on total attack frequency) on each prey size class is given in parentheses

\begin{tabular}{|c|c|c|c|c|c|c|}
\hline \multirow{3}{*}{$\begin{array}{l}\text { Crab carapace } \\
\text { width }(\mathrm{cm})\end{array}$} & \multicolumn{6}{|c|}{ Prey species and size class (shell height, $\mathrm{cm}$ ) } \\
\hline & \multicolumn{3}{|c|}{ Penmon Nucella lapillus } & \multicolumn{3}{|c|}{ Littorina littorea } \\
\hline & $1.0-1.5$ & $1.5-2.0$ & $2.0-2.5$ & $1.0-1.5$ & $1.5-2.0$ & $2.0-2.5$ \\
\hline 7.5 & $\begin{array}{c}0.14 \pm 0.14 \\
(1.00)\end{array}$ & $\begin{array}{c}0.14 \pm 0.14 \\
\text { (0) }\end{array}$ & $\begin{array}{l}0 \\
-\end{array}$ & $\begin{array}{c}2.28 \pm 0.42 \\
(0.87)\end{array}$ & $\begin{array}{c}2.43 \pm 0.48 \\
(0.59)\end{array}$ & $\begin{array}{c}1.86 \pm 0.26 \\
(0.38)\end{array}$ \\
\hline 7.8 & $\begin{array}{c}0.80 \pm 0.26 \\
(1.00)\end{array}$ & $\begin{array}{c}1.10 \pm 0.46 \\
(1.00)\end{array}$ & $\begin{array}{c}0.71 \pm 0.29 \\
(0.60)\end{array}$ & $\begin{array}{c}3.70 \pm 0.29 \\
(0.96)\end{array}$ & $\begin{array}{c}2.86 \pm 0.14 \\
(0.95)\end{array}$ & $\begin{array}{c}3.29 \pm 0.42 \\
(0.74)\end{array}$ \\
\hline 8.1 & $\begin{array}{c}0.71 \pm 0.29 \\
(1.00)\end{array}$ & $\begin{array}{c}0.43 \pm 0.20 \\
(0)\end{array}$ & $\begin{array}{c}0.72 \pm 0.36 \\
(0.40)\end{array}$ & $\begin{array}{c}2.70 \pm 0.64 \\
(1.00)\end{array}$ & $\begin{array}{c}2.60 \pm 0.37 \\
(1.00)\end{array}$ & $\begin{array}{c}1.86 \pm 0.55 \\
(0.70)\end{array}$ \\
\hline 8.2 & $\begin{array}{c}1.71 \pm 0.47 \\
(0.83)\end{array}$ & $\begin{array}{c}1.57 \pm 0.43 \\
(0.91)\end{array}$ & $\begin{array}{c}1.43 \pm 0.53 \\
(0.90)\end{array}$ & $\begin{array}{c}2.42 \pm 0.72 \\
(1.00)\end{array}$ & $\begin{array}{c}2.28 \pm 0.68 \\
(0.94)\end{array}$ & $\begin{array}{c}2.14 \pm 0.46 \\
(0.87)\end{array}$ \\
\hline
\end{tabular}

Time Period

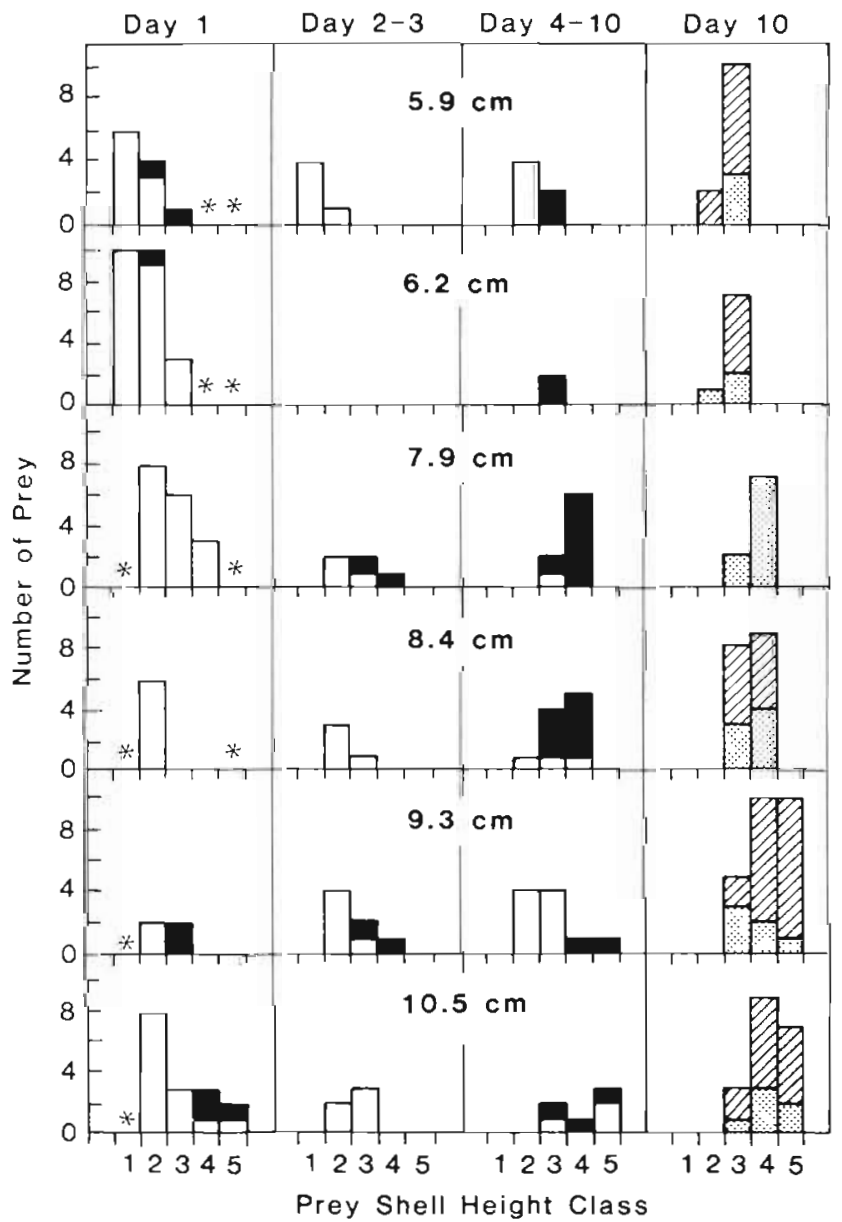

Fig. 7. Cancer pagurus. Prey-size selection on Church Island Nucella lapillus presented without replacement. Number of prey eaten (open bar) and number sustaining new injury (solid bar) in each of 3 time periods. Number of prey remaining intact after $10 \mathrm{~d}$ (hatched bar) and those alive, but bearing shell injury (stippled bar), also given. Prey shell height classes $(\mathrm{cm}): 1(0.5$ to 1.0$) ; 2(1.0$ to 1.5$) ; 3(1.5$ to 2.0$) ; 4(2.0$ to 2.5$)$; 5 (2.5 to 3.0); * size class not presented in a trial. Carapace width $(\mathrm{cm})$ of $\mathrm{crab}$ is indicated for each trial
C. productus (Kitching 1976, Bertness 1977, Zipser \& Vermeij 1978), C. irroratus (Beattie \& Elner 1982), C. borealis (Dudley 1980, Beattie \& Elner 1982) and C. gracilis (Vance 1972).

The equal facility with which Cancer pagurus held or broke prey with either chela contrasts with the specific roles associated with the cutter and crusher chelae of Carcinus maenas (Elner 1980) and other portunid crabs (Hughes \& Seed 1981, Du Preez 1984). Furthermore, no sexual differences in prey handling capability were detected for the juvenile C. pagurus used in the present study.

The critical sizes for crushing Nucella lapillus and Littorina littorea, beyond which Cancer pagurus uses apertural breakage, depend more on the shape than on the strength of the shell, probably reflecting a loss of grip and of mechanical advantage when holding larger shells. Thus the shell widths of these critical sizes are more closely matched than are shell height or resistance to compression (Table 4). Shell shape is also implicated in the susceptibility of medium-sized prey as crabs experienced difficulty in breaking open prey which had shell apertures approximating the crosssectional area of the dactyli. Shell thickness assumes greater importance in determining attack success as the critical size for apertural breakage is reached.

\section{Profitability}

Profitability curves derived from single regressions of yield and of breaking time on size of Church Island Nucella lapillus failed to account for the high profitabilities coinciding with the critical size for crushing (Fig. 5). A better fit was obtained using dual breaking time functions, based on the attack method used. A similar approach was used by Hughes \& Elner (1979) for Carcinus maenas feeding on $N$. lapillus and by 
gain a refuge in size from this species. Hughes \& Elner (1979) found a maximum size of $2.7 \mathrm{~cm}$ for sheltered shore Nucella lapillus successfully attacked by adult $C$. maenas and noted that Church Island $N$. lapillus above $1.0 \mathrm{~cm}$ were immune to $C$. maenas predation. The present study reveals a much more limited potential for the attainment of a size refuge from Cancer pagurus predation, particularly for L. littorea. Even on reaching a size of $2.0 \mathrm{~cm} \mathrm{~L}$. littorea could be opened by C. pagurus as small as $5.6 \mathrm{~cm}$ (Fig. 1B).

Predatory impact in the field will depend on the sizefrequency distribution and relative abundances of crabs on different shores; it may be expected that an equilibrium between adaptation and pressure has been reached for most gastropod populations (Hughes $\&$ Elner 1979). The 2 sheltered shores examined in this study, Penmon and Church Island, have similar densities of Cancer pagurus, but differ in population size-frequency distribution (Table 1; Lawton 1983). Adult Penmon Littorina littorea may be vulnerable to large $C$. pagurus (Fig. 1B), but it is unlikely that they are exposed to predation from this source. Nonetheless, medium-sized C. pagurus, which are found at Penmon, maintained high predation rates on Penmon L. littorea when offered singly (Table 2) and when offered together with Nucella lapillus (Table 3).

Hughes \& Elner (1979) record predation rates for adult Carcinus maenas (6 to $6.95 \mathrm{~cm}$ ) on Nucella lapillus from Trwyn-y-Penrhyn (Map ref. SH 629797), a sheltered shore approximately $1 \mathrm{~km}$ from Penmon. These data may be compared with those obtained in the present study for medium-sized Cancer pagurus $(7.5$ to $8.5 \mathrm{~cm})$ feeding upon Penmon $N$. lapillus. The mean numbers of gastropods eaten (gastropods $d^{-1} \pm$ $\mathrm{SE}$ ) from the size classes common to both studies are shown in Table 5. A larger size class of $N$. lapillus $(2.5$ to $2.99 \mathrm{~cm}$ ) was presented to $C$ maenas, but few prey were taken $\left(0.03 \pm 0.02\right.$ gastropods $\left.d^{-1}\right)$. Mediumsized $C$. pagurus exerted the above predation rates in addition to the consumption of small $N$. lapillus (1.0 to $1.49 \mathrm{~cm}$ ) at a rate of $1.8 \pm 0.23$ gastropods $\mathrm{d}^{-1}$.

Carcinus maenas may exert selection against weaker shells in gastropod populations by adopting a foraging strategy of attacking all encountered prey but

Table 5. Carcinus maenas and Cancer pagurus. Rates of predation on 2 size classes of gastropod

\begin{tabular}{|ccc|}
\hline $\begin{array}{l}\text { Prey shell height } \\
(\mathrm{cm})\end{array}$ & $\begin{array}{c}\text { Predation rate } \\
\left.\text { (gastropods } \mathrm{d}^{-1} \pm \mathrm{SE}\right) \\
\text { Carcinus maenas }\end{array}$ & Cancer pagurus \\
\hline $1.5-1.99$ & $0.4 \pm 0.20$ & $0.9 \pm 0.33$ \\
$2.0-2.49$ & $0.02 \pm 0.01$ & $0.5 \pm 0.18$ \\
\hline
\end{tabular}

quickly rejecting those that do not yield (Hughes \& Elner 1979). The present finding that Cancer pagurus persists for long periods in attacks on gastropods, frequently inflicting damage on relatively large, strong shells, provides a mechanism for greater selection pressure and corroborates the hypothesis stated by Hughes \& Elner (1979), that the massive shells of sublittoral fringe Nucella lapillus at Church Island have resulted from C.pagurus predation. The less extreme morphological adaptation in the Penmon morph parallels the variation in C. pagurus size-frequency distribution between these 2 shores.

Reduced levels of morphological adaptation in Littorina littorea lead to increased susceptibility to crab predation and differential predation on this species when offered together with Nucella lapillus. In the present experiments $L$. littorea were immobilized by heat coma and so were unable to exploit their escape reaction of climbing upwards out of reach of predators (Hadlock 1980). Relatively lower predation rates have been recorded for other crabs, Cancer borealis and C. irroratus, preying on naturally mobile $L$. littorea (Beattie \& Elner 1982). Behavioural escape responses have been reported for other gastropods having pelagic dispersal phases (Schmitt 1981, Watanabe 1983), which suggests that behavioural responses to predation pressure may not be constrained to the same extent as morphological adaptations are (Currey \& Hughes 1982) by gene flow between populations (Lawton 1983).

Acknowledgements. We thank 3 anonymous reviewers for perceptive comments on an earlier draft of this paper; $R$. W Elner and T. ap Rheinallt for reviewing the revised manuscript. P. L. was supported by a University of Wales postgraduate research studentship.

\section{LITERATURE CITED}

Arnold, W S. (1984). The effects of prey size, predator size, and sediment composition on the rate of predation of the blue crab, Callinectes sapidus Rathbun, on the hard clam, Mercenaria mercenaria (Linné). J. exp. mar. Biol. Ecol. 80: 207-219

Beattie, M., Elner, R. W. (1982). Predation on the periwinkle, Littorina littorea, by northwestern Atlantic crabs and lobsters. Malacol. Rev, 15: 145

Bertness, M. D. (1977). Behavioral and ecological aspects of shore level size gradients in Thais lamellosa and Thais emarginata. Ecology 58: 86-97

Blundon, J. A., Kennedy, V. S. (1982). Mechanical and behavioral aspects of blue crab, Callinectes sapidus (Rathbun), predation on Chesapeake Bay bivalves. J. exp. mar. Biol. Ecol. 65: 47-65

Currey, J. D., Hughes, R. N. (1982). Strength of the dogwhelk Nucella lapillus and the winkle Littorina littorea from different habitats. J. Anim. Ecol. 51: 47-56

Dudley, R. (1980). Crab crushing of periwinkle shells, Lit- 
torina littorea, from two adjacent geographical provinces. Nautilus 94: 108-111

Du Preez, H. H. (1984). Molluscan predation by Ovalipes punctatus (De Haan) (Crustacea: Brachyura: Portunidae). J. exp. mar. Biol. Ecol. 84: 55-71

Elner, R. W (1980). The influence of temperature, sex and chela size in the foraging strategy of the shore crab, Carcinus maenas (L.). Mar. Behav. Physiol. 7: 15-24

Elner, R. W., Hughes, R. N. (1978). Energy maximization in the diet of the shore crab, Carcinus maenas. J. Anim. Ecol. 47: $103-116$

Elner, R. W., Raffaelli, D. G. (1980). Interactions between two marine snails, Littorina rudis Maton and Littorina nigrolineata Gray, a predator Carcinus maenas (L.), and a parasite Microphallus similus Jägerskiold. J. exp. Mar. Biol. Ecol. 43: 151-160

Hadlock, R. P. (1980). Alarm response of the intertidal snail Littorina littorea (L.), to predation by the crab, Carcinus maenas (L.). Biol. Bull, mar. biol. Lab., Woods Hole 159: 269-279

Hughes, R. N. (1972). Annual production of two Nova Scotian populations of Nucella lapillus (L.). Oecologia (Berl.) 8: 356-370

Hughes, R. N. (1979). Optimal diets under the energy maximization premise: the effects of recognition time and learning. Am. Nat. 113: 209-221

Hughes, R. N. (1980). Optimal foraging theory in the marine context. Oceanogr. mar. Biol. A. Rev. 18: 423-481

Hughes, R. N., Elner, R. W. (1979). Tactics of a predator, Carcinus maenas and morphological responses of the prey, Nucella lapillus. J. Anim. Ecol. 48: 65-78

Hughes, R. N., Seed, R. (1981). Size selection of mussels by the blue crab Callinectes sapidus: energy maximizer or time minimizer? Mar. Ecol. Prog. Ser. 6: 83-89

Hylleberg, J., Christensen, J. T (1978). Factors affecting the intra-specific competition and size distribution of the periwinkle, Littorina littorea (L.). Natura jutl. 20: 193-202

Jubb, C. A., Hughes, R. N., ap Rheinallt, T (1983). Behavioural mechanisms of size selection by crabs, Carcinus maenas (L.) feeding on mussels, Mytilus edulis L. J. exp. mar. Biol. Ecol. 66: 81-87

Kitching, J. A. (1976). Distribution and changes in shell form of Thais spp. (Gastropoda) near Bamfield, B. C. J. exp mar. Biol. Ecol. 23: 109-126
Lawton, P. (1983). The feeding biology of the edible crab, Cancer pagurus L. Ph. D. thesis, Univ. of Wales, Bangor

Lawton, P., Elner, R. W. (1985). Feeding in relation to morphometrics within the genus Cancer evolutionary and ecological considerations. Proc. of the Symp. on Dungeness Crab Biology and Management. Alaska Sea Grant Rep. 85-3: 357-379

Lewis, J. R. (1964). The ecology of rocky shores. English Univ. Press, London

Mittelbach, G. G. (1981). Foraging efficiency and body size: a study of optimal diet and habitat use by bluegills. Ecology 62: 1370-1386

Pyke, G. H., Pulliam, H. R., Charnov, E. L. (1977). Optimal foraging: a selective review of theory and tests. $Q$. Rev. Biol. 52: 137-154

Pyke, G. H. (1984). Optimal foraging theory: a critical review. Ann. Rev. Ecol. Syst. 15: 523-575

Siegel, S. (1956). Nonparametric statistics for the behavioral sciences. McGraw-Hill Book Co., New York

Schmitt, R. J. (1981). Contrasting antipredator defenses of sympatric marine gastropods. J. exp. mar. Biol. Ecol. 54: 251-264

Vance, R. R. (1972). The role of shell adequacy in behavioral interactions involving hermit crabs. Ecology 53: $1075-1083$

Vermeij, G. J. (1976). Interoceanic differences in vulnerability of shelled prey to crab predation. Nature, Lond. 260: $135-136$

Vermeij, G. J. (1977). Patterns in crab claw size: the geography of crushing. Syst. Zool. 26: 138-151

Warner, G. F., Jones, A. R. (1976). Leverage and muscle type in crab chelae (Crustacea: Brachyura). J. Zool., Lond. 180: $57-68$

Watanabe, J. M. (1983). Anti-predator defenses of three kelp forest gastropods: contrasting adaptations of closelyrelated prey species. J. exp. mar. Biol. Ecol. 71: 257-270

Zar, J. H. (1974). Biostatistical analysis. Prentice-Hall Inc, Englewood Cliffs, New Jersey

Zipser, E., Vermeij, G. J. (1978). Crushing behaviour of tropical and temperate crabs. J. exp. mar. Biol. Ecol. 31: $155-172$

This paper was presented by Dr. B. L. Bayne; it was accepted for printing on August 16, 1985 